\title{
Electronic cigarette: a possible substitute for cigarette dependence
}

\author{
P. Caponnetto1,2, C. Russo1,2, C.M. Bruno2, A. Alamo1,2, \\ M.D. Amaradio 1,2 , R. Polosa 1,2
}

\begin{abstract}
Electronic cigarette: a possible substitute for cigarette dependence. P. Caponnetto, C. Russo, C.M. Bruno, A. Alamo, M.D. Amaradio, R. Polosa.

Cigarette smoking is the leading cause of premature mortality in western countries and it is important for smokers to stop as early as possible. Electronic cigarettes are a popular phenomenon of global proportion. Recent uncontrolled studies, reported that a certain number of smokers have quit using electronic cigarettes. This could hint a role
\end{abstract}

for electronic cigarettes to be used for smoking cessation, and therefore merits further evaluation for this purpose. Besides vaporising nicotine to be inhaled, electronic cigarettes may also provide a coping mechanism for conditioned smoking cues by replacing some of the rituals associated with smoking gestures, and for these reasons cigarette could become a tool - if studied more extensively - in the fight against tobacco-related morbidity and mortality. Monaldi Arch Chest Dis 2013; 79: 1, 12-19.

Keywords: Nicotine addiction, Smoking cessation, Smoking reduction, Electronic cigarettes, Tobacco harm reduction.

${ }^{1}$ Centro per la Prevenzione e Cura del Tabagismo (CPCT), Azienda Ospedaliero-Universitaria "Policlinico V. Emanuele", Università di Catania, Catania;

2 Institute of Internal Medicine, Azienda Ospedaliero-Universitaria "Policlinico V. Emanuele”, Università di Catania, Catania, Italy.

Correspondence: Prof. Riccardo Polosa, MD, PhD, UOC di Medicina Interna, Edificio 4, Piano 3, AOU “Policlinico V. Emanuele", Università di Catania, Via S.Sofia 78,95123 Catania, Italy; e-mail: polosa@unict.it

\section{Introduction}

Tobacco addiction is the leading cause of preventable premature mortality across the globe with approximately 5 million tobacco-related deaths per annum [1]. Death is principally caused by cancers, chronic obstructive pulmonary disease (COPD), lung and ischemic heart disease (IHD) [2, 3]. Depending on the different diseases, short and long term abstinence is known to decrease significantly the peril of these diseases $[3,4]$.

Contemporary strategies to encourage smoking cessation range from simple medical advice to pharmacotherapy and counselling [5]. Counselling and drugs are effective when used by themselves for treating tobacco addiction, but the combination of counselling and medication is more effective than either alone [5]. Consequently, clinicians should encourage all smokers attempting to quit to use both counselling and medication. It should be noted that treatments aimed at smoking cessation are among the most cost effective interventions in health care [6].The potent addictive qualities of nicotine produce a huge hurdle, even for those with a real wish to quit smoking. Approximately $80 \%$ of smokers who attempt to quit on their own relapse within the first month of cessation, and only about 3-5\% remain abstinent at 24 week [7]. Additionally, smoking cessation medications currently available such as nicotine replacement therapy, the atypical antidepressant bupropion and the partial agonist of the $\alpha 4 \beta 2$ nicotinic acetylcholine receptor, varenicline, at best double or triple this quit rate under the ideal circumstances of a research setting but have had low uptake and inferior efficacy in a real life setting [5,8]. Moreover, bupropion and varenicline have come under increased scrutiny due to reports of serious adverse events that include behaviour alteration, depression, self-injurious thoughts, and suicidal behaviour [9]. The Tobacco Advisory Group of the Royal College of Physicians acknowledges that the advance of addiction includes modifications in behaviour together with changes in mind, structure and function that harm the capacity to achieve and sustain abstinence. They note that some of these changes may not be completely reversible [10]. Finally, even tobacco control policies - particularly when not integrated and supported by adequate funding - are not very effective [11].

Consequently, there are 5 million tobacco-related deaths per annum. Many smokers will keep smoking until they die from it because when given only the options of smoking or completely giving up nicotine, many will not give it up. Nicotine per se does not cause much risk when separated from inhaling cigarette smoke, it is important to consider that another choice is also presented to smokers; the reduction of smoking-related diseases by assuming nicotine in a low risk form.

A new approach is needed; can electronic cigarette be a possible solution? The electronic ciga- 
rette is a cigarette shaped electronic creation, produced and marketed by numerous companies, powered by a lithium-ion re-chargeable battery that is designed to vaporise nicotine to be inhaled [12]. Besides vaporising nicotine to be inhaled, electronic cigarettes may also provide a coping mechanism for conditioned smoking cues by replacing some of the rituals associated with smoking gestures (e.g. hand-to-mouth action of smoking), and for these reasons it is now perceived by users as a potentially more attractive substitute for smoking than low toxin smokeless tobacco [13]. Electronic cigarettes use the process of vaporisation rather than combustion and for this reason this tool could be used as a lower risk substitute for traditional cigarettes because tobacco combustion is not necessary for its operation. Additionally, smokers report buying electronic cigarettes to help quit smoking traditional cigarette, to reduce cigarette consumption, to alleviate nicotine withdrawal symptoms due to workplace smoking restrictions, and to continue having a 'smoking' experience, but with reduced health risks [14]. Electronic cigarette is a popular phenomenon of global proportion [15] that calls for further research, legislation, and product development.

The focus of the present article is about the health effects of using an electronic cigarette, with consideration given to the acceptability, safety and effectiveness of this product to serve as a longterm substitute for smoking or as a tool for smoking cessation.

\section{Electronic cigarette: a rapidly growing phenomenon}

Nicotine Replacement Therapy (NRT), the most frequent smoking-cessation product, aimed at aiding smoking cessation by reducing the severity of smoking withdrawal symptoms and cigarettes cravings, do not fully control all the symptoms of withdrawal because the available delivery systems do not reproduce the rapid and high levels of nicotine achieved through cigarette use [16, 17]. Different types of NRT (nicotine lozenge, gum, patch, nasal spray, and inhaler) could have a distinct role upon either withdrawal symptoms or urges to smoke, but there is little direct evidence that one nicotine product is more effective than another. However, it is possible that electronic-cigarettes, that resemble a traditional cigarette may deliver aerosolised nicotine in a more efficient manner. Moreover, efficacy with NRTs, as with other anti-smoking medication, is modest because it addresses only the physical component of cigarette smoking (i.e. nicotine dependence), and is unlikely to resolve the psychological factors (cognitive and behavioural including handling, holding and puffing a cigarette) associated with cigarette smoking [18, 19]. When the smoker quits, those rituals are no longer there, but the need for the ritual still exists. Given that both nicotine and smoking related cues appear to control cigarette craving and withdrawal symptoms, electronic cigarettes - by supplying nicotine and by mimicking the ritu- als associated with cigarette smoking - may be used as an efficient smoking cessation appliance [20].

In two studies we have reported objective measures of long term smoking cessation in five heavy smokers with high nicotine dependence with and without major depression, who quit after taking up an electronic cigarette. These heavy smokers who were treated before for smoking cessation, used ecigarettes on their own and reported during a follow-up telephone interview to have quit smoking. Following this telephone call, all cases were admitted to our smoking cessation clinic to assess their exhaled-CO measured $[21,22]$. This is important in consideration of the fact that this was accomplished without the use of recommended nicotine dependence treatments and smoking cessation counselling, and who had repeatedly failed in previous attempts when provided with professional smoking cessation assistance at our smoking cessation clinic. In a recent research, we observed possible change in smoking habits of 40 smokers not willing to quit using an electronic cigarette [23]. Combined six months smoking abstinence and smoking reduction was shown in 22/40 (55\%) smokers. The fact that 22 smokers unwilling to quit eventually switched to the electronic cigarette or quit altogether for 6 months needs to be explained. Although the results presented are encouraging, large and carefully conducted prospective randomised controlled trials will be required before a definite answer about the efficacy and safety of electronic-cigarettes can be reached. Some research is already in progress in Italy and New Zealand and hopefully it will be able to confirm and expand the preliminary clinical knowledge of electronic-cigarettes.

\section{Health analysis about electronic cigarettes}

\section{Toxicology}

Complete toxicology characterisation of the elements contained in electronic cigarettes' liquid and vapour using gas chromatography mass spectrometry (GC-MS) is accumulating quickly and shows that their primary components are propylene glycol (PG), water, nicotine and glycerine [24]. PG is approved by Food and Drug Administration (FDA) for a variety of pharmaceuticals formulation. It has undergone extensive testing and is widely used in a variety of consumer products including food [25].

In a classic study, Laugesen tested electronic cigarette mist for over 50 priority-listed cigarette smoke toxicants and found none [26]. This research only revealed minimal traces of Tobaccospecific Nitrosamines (TSNAs) in the "high" nicotine cartridge of a Ruyan brand electronic cigarette similar to the quantity reported to be present in a nicotine medicinal patch.

In an recent report, laboratory analyses carried out by the US Food and Drug Administration (FDA) failed to find carcinogens and toxic chemicals in most of the electronic cigarettes tested with a single exception: about $1 \%$ of diethylene glycol 
(DEG) were detected in the liquid of one of the 18 samples, however this not represent a toxic quantity $[24,25]$.

Another independent analysis of the same electronic cigarette products tested by the FDA found no evidence of carcinogenic TSNAs in their aerosol [27]. The fact, highlighted by FDA, that there is no quality control in the making of several E-cigarettes can be a cause for different findings in different analyses of the same product.

A further study conducted by Cahn and Siegel have reviewed the evidence regarding the safety of the liquid in electronic cigarettes [28]. TSNAs were reported in two studies, but at trace levels, similar to those found in a nicotine patch, were most importantly, about 500-fold to 1400-fold lower than TSNA levels measured in regular cigarettes (electronic cigarettes containing only 0.07 $0.2 \%$ of the TSNAs present in tobacco cigarettes) (table 1). This is an important factor. Electronic cigarettes deliver a nicotine vapour without the combustion products that is responsible for nearly all of smoking's harmful effects. Temperatures of up to 950 degrees are generated with each puff of a lit cigarette and some 5000 or so chemicals, many of which are toxic or carcinogenic, are generated during the combustion process [29]. Electronic cigarettes use the process of vaporisation rather than combustion and the low operating temperature of the atomiser (about $50-60^{\circ} \mathrm{C}$; approx. $5-10 \%$ of the temperature of a lit cigarette) suggests that these products as a class are unlikely to emit cigarette toxicants in their mist [25].

\section{General safety data}

In a recent study on safety assessment of electronic cigarettes smokers, researchers found no abnormal changes in blood pressure, haematological data, or blood chemistry and no severe adverse events after 4 weeks of regular electronic cigarettes use [30]. Our clinical safety assessment of electronic cigarette in 40 smokers showed that dry cough, mouth and throat irritation were commonly reported in the initial four weeks of use, but all appeared to wane spontaneously by the end of the study, after 24 weeks of regular use [23] (figure 1). These are likely to be due to exposure to propylene glycol mist generated by the electronic cigarettes's atomizer. Exposure to propylene glycol mist may occur from smoke generators in discotheques, theatres, and aviation emergency training and is known to cause ocular, mouth, throat, upper airway irritation and cough $[31,32]$. Dizziness was frequently reported by smokers at the beginning of the research and can be brought about by the hyperventilation associated to the greater puffing time with the electronic cigarette. The considerable reduction in the occurrence of dizziness observed by the end of the study may be due to the improved familiarisation with the puffing technique.

Additionally, traditional cigarette smoking reduction by mean the electronic cigarette under study led to an important decrease in exhaled carbon monoxide (CO) levels [23].

Surprisingly, typical cigarette withdrawal symptoms were not reported during the course of the research. It is probable that the electronic cigarette by providing a coping mechanism for conditioned smoking cues could alleviate typical cigarette withdrawal symptoms associated with cigarette smoking reduction and cigarette smoking abstinence as shown for nicotine-free inhalators [33].

In a recent study Vardavas et al [34], concluded that: "Electronic Cigarette assessed in the context of this study were found to have immediate adverse physiologic effects after short term use that are similar to some of the effects seen with tobacco smoking, however the long term health effects

Table 1. - Summary data of maximum tobacco-specific nitrosamine levels in various cigarettes and nicotinedelivery products including electronic cigarettes (ng/g, except for nicotine gum and patch that are $\mathrm{ng} / \mathrm{gum}$ piece and ng/patch) [Modified by Chan Z et al. J Public Health Policy 2011]

\begin{tabular}{lcccc}
\hline Product & NNN & NNK & NAT & NAB \\
\hline Nicorette gum (4 mg) & 2.00 & ND & ND & ND \\
\hline NicoDerm CQ patch (4 mg) & ND & 8.00 & ND & ND \\
\hline Electronic cigarettes & $\mathbf{3 . 8 7}$ & $\mathbf{1 . 4 6}$ & $\mathbf{2 . 1 6}$ & $\mathbf{0 . 6 9}$ \\
\hline Swedish snus & 980.00 & 180.00 & 790.00 & 60.00 \\
\hline Winston (full) & 2200.00 & 580.00 & 560.00 & 25.00 \\
\hline Marlboro (full) & 2900.00 & 960.00 & 2300.00 & 100.00 \\
\hline Camel (full) & 2500.00 & 900.00 & 1700.00 & 91.00 \\
\hline Marlboro (ultra-light) & 2900.00 & 750.00 & 1100.00 & 58.00
\end{tabular}

NNN = 4-(methylnitrosamino)-1-(3-pyridyl)-1-butanone; NNK = N'-nitrosonornicotine; NAT = N'-nitrosoanatabine; NAB = N'-nitrosoanabasine; ND = Not detected. 


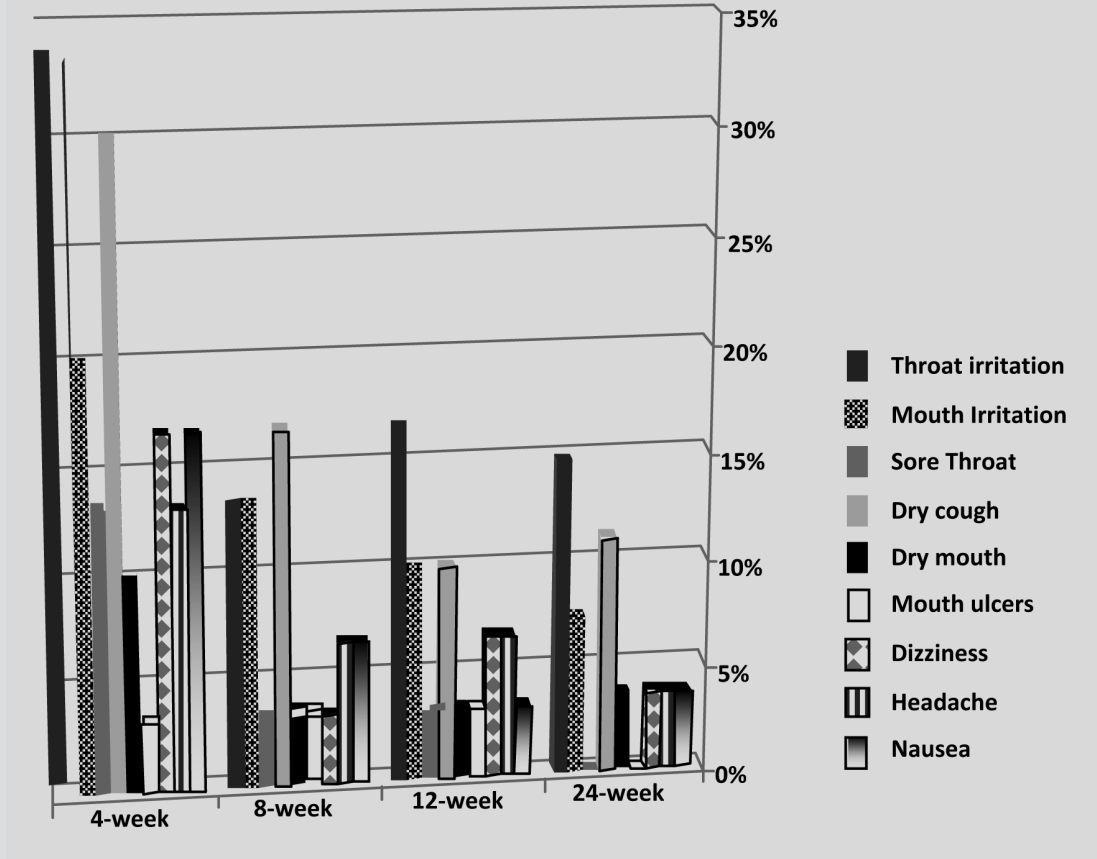

Fig. 1. - Adverse events reported by electronic cigarette users who completed all study visits [Modified from ref. 23].

of e-cigarette use are unknown but potentially adverse and worthy of further investigation".

Unfortunately, the work illustrated by Vardavas and colleagues [34] are not conclusive due to the number of subjects studied (30 cases and 10 controls) and, the choice of study outcomes of unclear clinical relevance.

The reported $16 \%$ decrease in FeNO (i.e. 2.1 ppb in absolute term) and $11 \%$ increase in peripheral flow resistance (IOS) (i.e. $0.025 \mathrm{kPa} / \mathrm{L} / \mathrm{s}$ in $\mathrm{ab}-$ solute term) after e-cigarette use from baseline are so small and well within tests variability $[35,36]$ that it is highly unlikely to have meaningful adverse effects. It should be notedthat no changes were detected by canonical pulmonary function testing after e-cigarette use. Moreover, the small changes in FeNO and IOS may be non-specific. The mist generated by the e-cigarette per se might have contributed to these changes. Nebulization of saline per se can reduce FeNO from baseline. Consequently, authors should have included a more pertinent control (e.g. saline mist generated by an ultrasonic nebulizer) in their study. Also, another reasonable comparator that should have been used as control could have been the participants' own brand cigarette.

The data noted above suggests that electronic cigarettes are safer than tobacco cigarettes [28] and comparable in terms of tobacco-specific nitrosamines (TSNAs) levels to conventional nicotine replacement products [37]. Despite these important results, large and well conducted long-term studies will be required before a complete answer regarding the safety of electronic cigarettes can be formulated [20]. In fact, this tool appears to be much safer than traditional cigarettes and comparable in toxicity to conventional nicotine replacement products [28].

\section{The role of nicotine}

Nicotine fulfils all the criteria of an addictive agent, including psycho-active effects, compulsive use, relapse after abstinence, drug-reinforced behaviour, physical dependence and tolerance. Nicotine stimulates dedicated receptors in the brain which create both sedative and euphoric effects [38]. Individuals who have mood dysfunctions or attention deficits are more likely to start smoking and less likely to be able to stop smoking. Nicotine has useful effects on attention, concentration, and mood and smokers who have mood dysfunctions or attention deficits may be depending on nicotine as a means of selfmedication [39].

Nicotine is a sympathomimetic drug that releases catecholamine, increases heart rate and cardiac contractility, constricts cutaneous and coronary blood vessels, and transiently increases blood pressure. It also reduces sensitivity to insulin and may aggravate or precipitate diabetes, and may contribute to endothelial dysfunction. These various effects on the cardiovascular system could, in theory, promote atherogenesis and precipitate acute ischemic events in people who have coronary artery disease. This has been of particular concern in smokers who use nicotine medication while they are still smoking. However, increased cardiovascular risk due to nicotine medication does not appear to be a problem [40]. Nicotine is not a direct carcinogen, but there are concerns that it may be a tumour promoter. Whether nicotine is a cancer promoter in people has not been established [40]. Suspected adverse reproductive effects of nicotine include most prominently fetal neuroteratogenic effects. In general, it is not desirable to use nicotine during pregnancy, but if the alternative is cigarette smoking, then nicotine medication is less hazardous [40]. Nicotine replacement therapy used long term is well-tolerated without evidence of serious adverse health effects [41]. In conclusion, nicotine per se does not cause much risk when separated from inhaling smoke.

\section{Effect of an electronic nicotine delivery device (e-cigarette) on smoking habits}

Contemporary smoking cessation treatments can increase the chance of quitting in committed smokers who are already motivated and prepared to stop smoking [42], but a broader range of strategies are needed in order to bring more smokers into treatment and increase the numbers who are motivated to make quit attempts. Although not for- 
mally regulated as a pharmaceutical product, the preliminary positive results with electronic cigarettes could be confirmed and expanded in classic smoking cessation trials of smokers motivated to quit.

The most frequent smoking-cessation treatment is nicotine replacement therapy, which is aimed at addressing nicotine dependence [43]. NRT does not completely control all symptoms of withdrawal because the available delivery systems do not reproduce the rapid and high levels of nicotine achieved through tobacco use [16, 17]. Its principal mechanism of action is to replace partially the nicotine formerly obtained from cigarette smoking, and this aids smoking cessation by attenuating the reinforcing effects of nicotine delivered via tobacco, and therefore reduces the severity of cigarette withdrawal symptoms and cravings [44]. Nicotine lozenge, nicotine gum, nicotine patch, nicotine nasal spray, and nicotine inhaler could have a distinct impact upon either withdrawal symptoms or urges to smoke, but there is little direct evidence that one NRT product is more effective than another, perhaps with the only exception of the nicotine nasal spray [5]. It is possible that the electronic cigarette may deliver aerosolised nicotine in a more efficient manner compared to NRT. Moreover, efficacy with NRT, as for other antismoking medications like bupropion or varenicline, is modest because it addresses only the physical component of smoking (i.e. nicotine dependence), and is unlikely to resolve the psychological factors (cognitive, and behavioural including handling, holding and puffing a cigarette) associated with cigarette smoking [18, 19]. When the smoker quit, those rituals are no longer there, but the need for the ritual still exists and this is an important cause of early relapse. Given that both smoking related cues and nicotine appear to control withdrawal symptoms and cigarette craving, electronic cigarettes - by supplying nicotine and by mimicking the rituals associated with traditional cigarette smoking - may be used as an helpful smoking cessation device [21-23]. Also, when we bear in mind that nicotine per se does not cause much risk when separated from inhaling cigarettes smoke, switching to the electronic cigarette equates to quitting in exposure terms.

An internet survey, conducted by Etter and Bullen, supports the idea that electronic cigarettes may be effective in smoking cessation. In this survey of 3587 electronic cigarettes users [45], most respondents (up to 96\%) reported the electronic cigarette helped them quit smoking or reduce their smoking. They also said electronic cigarettes were used to avoid relapse. Most ex-smokers in the sample $(79 \%)$ feared they might relapse to smoking if they stopped using the electronic cigarette.

A second online survey [46] enrolled 303 users, most of whom lived in the US (72\%) or Europe $(21 \%)$, via email and links on various blogs and forums. This survey was conducted by a UK electronic cigarette company and the data was evaluated by independent university researchers. Most (79\%) were using electronic cigarettes as a complete replacement for smoking, with another $17 \%$ using them as a partial replacement. Health improvements were reported for general health $(91 \%)$, smoker's cough (97\%), and ability to exercise $(84 \%)$, and none reported that these were worse.

In a third survey [47], the 6-month point prevalence of smoking abstinence among the 222 electronic cigarettes users was of $31 \%$. Of those using the electronic cigarette more than 20 times per day, $70 \%$ were non-smokers at 6 months.

A further research [48] surveyed 257 users in Poland to investigate patterns of use. Of the 170 users who completed the survey, $83 \%$ were regular smokers when they began using electronic cigarettes, and $66 \%$ declared they were not smoking. Almost all (98\%) used their electronic cigarettes every day. Nicotine levels used ranged from zero nicotine $(3 \%)$ to higher than $16 \mathrm{mg}$ per cartridge (25\%), with $41 \%$ using $8-16 \mathrm{mg}$ per cartridge.

These studies, showed that a certain number of smokers quit using electronic cigarettes and therefore merits further evaluation for this purpose.

\section{Electronic cigarette and its role in the fight against tobacco-related morbidity and mortality}

When given only the options of smoking cigarettes or completely giving up nicotine, many smokers will not give it up and will keep on smoking thus exposing themselves to increasing health risks. However, if it considered that nicotine per se does not cause much risk, a third possible option is also presented to smokers; the reduction of smoking-related diseases by taking nicotine in a low risk form. Tobacco Harm reduction (THR), the substitution of low risk nicotine products for cigarette smoking, is likely to offer huge public health benefits. Harm reduction is particularly compelling for the use of nicotine because so many people have such a strong inclination for using it. Actually THR is perhaps the most complex, controversial and divisive issue in tobacco control today [49].

As well the realistic example of Swedish snus (a type of finely ground moist snuff that delivers significant levels of nicotine) as a successful THR strategy [50-52], electronic cigarettes may prove to be an even more attractive long-term alternative because of their similarities to traditional cigarettes smoking, including the hand-to-mouth repetitive motion and the visual cue of a smoke-like vapour.

However, electronic cigarettes need to be improved for different reasons like its heaviness compared to classic cigarette and battery recharge.

Of course, these products may contribute to nicotine dependence, but the desire of a cigarette - free world is just that - a dream. This is because of the established nicotine's beneficial effects, such as the improved ability to pay attention, concentrate and remember, as well as the capacity of relieving symptoms of mood impairments [36].

Several studies $[45,46,53]$ paint a profile of the typical electronic cigarettes consumer as a long-term smoker who tried repeatedly to quit. 
The median age of respondents ranges from late $30 \mathrm{~s}$ to mid $40 \mathrm{~s}$. The percentage of respondents using electronic cigarette as a complete replacement for traditional cigarettes smoking ranges from $31 \%$ to over $79 \%$. Most who did not stop smoking completely reduced the number of cigarettes smoked. Over $90 \%$ reported that their health status had improved. When asked the main reason why they chose to use an electronic cigarette, $64.6 \%$ stated "to continue to have a 'smoking' experience, but with reduced health risks".

Although much more long term studies are needed, early results indicate that electronic cigarettes could be effective for helping long-term, heavy smokers to abstain from inhaling smoke.

\section{Conclusions}

According to the World Health Organisation (WHO) Framework Convention on Tobacco Control (FCTC) a significant reduction in the health burden of tobacco in the medium term may be obtained by encouraging cessation among smokers [54]. Therefore, a broader range of strategies are needed in order to fight against tobacco-related morbidity and mortality.

Unfortunately, efficacy of evidence based smoking cessation treatments is modest and far too many smokers are unwilling or unable to quit. Electronic cigarettes, for its specific characteristics, could be used as a lower risk substitute for tobacco cigarettes. This tool may prove to be a hopeful solution for reduction in the use of traditional cigarettes and their related risk, with the pros of these products clearly outweighing the cons (table 2).

This electronic device delivers a nicotine vapour without the combustion products that are responsible for nearly all of smoking's harmful effects. It use the process of vaporisation rather than combustion and the low operating temperature of the atomizer (less than $80^{\circ} \mathrm{C}$ ) suggests that this tool are unlikely to emit cigarette toxicants [25]. In contrast, temperatures of up to 950 degrees are generated with each puff of a lit cigarette and some 5000 or so chemicals, many of which are toxic or carcinogenic, are generated during the combustion process [29].

Although the reduction in health risks for people who use electronic cigarettes has not been quantified, we estimate it as similar to that reported for smokeless tobacco, which has approximately $1 \%$ of the death risk of smoking [55]. E-cigarettes may contain nicotine, which contributes to cigarette addiction and helps sustain tobacco use. However, if many smokers, not willing to quit, can convey their cigarette dependence to a less-harmful delivery method, millions of live could be saved around the world.

Clearly, these tools need to be effectively regulated, but thus far, there have been diverse regulatory responses ranging from no regulation to complete bans. WHO's Study Group on Tobacco Product Regulation advised a precautionary approach to electronic cigarettes [56] and, with a small number of exceptions, most national regulatory agencies have also adopted an analogous approach. The experimental basis for this regulatory approach is vague, and more appropriate research

Table 2. - Positive and negative aspects of e-cigarettes

\begin{tabular}{|c|c|}
\hline Positive & Negative \\
\hline $\begin{array}{l}\text { Beneficial effects on health } \\
\text { (improved breathing and less cough) }\end{array}$ & $\begin{array}{l}\text { Small percent of the population is sensitive } \\
\text { to propylene glycol (dry mouth and throat) }\end{array}$ \\
\hline No tobacco smoke odour or bad breath & Some flavours (e.g. piña colada) have a lingering fragrance \\
\hline Less toxic than tobacco smoke & Trace amounts of TSNAs present in some formulas \\
\hline Mimics sensation in the throat of inhaling smoke & $\begin{array}{l}\text { Throat sensation dependent on hardware used } \\
\text { and liquid composition }\end{array}$ \\
\hline The gestures or actions similar to smoking & $\begin{array}{l}\text { Equipment is heavier than traditional cigarette } \\
\text { and puffing technique requires some training }\end{array}$ \\
\hline Facilitates smoking abstinence & $\begin{array}{c}\text { Some users only manage to reduce the number } \\
\text { of cigarettes smoked }\end{array}$ \\
\hline $\begin{array}{l}\text { Relieves withdrawal symptoms and craving } \\
\text { for tobacco }\end{array}$ & $\begin{array}{l}\text { Relief of withdrawal symptoms varies, affected by quality } \\
\text { of equipment and nicotine strength of liquid }\end{array}$ \\
\hline $\begin{array}{l}\text { By and large, no risk to bystanders } \\
\text { Can be used everywhere }\end{array}$ & $\begin{array}{l}\text { Due to few studies on potential risk to bystanders, } \\
\text { some communities are outlawing indoor use }\end{array}$ \\
\hline No ash, dirt, or burned clothes & $\begin{array}{l}\text { Environmental concern about safe disposal } \\
\text { of cartridges and batteries }\end{array}$ \\
\hline $\begin{array}{l}\text { Accessible prices (in the long run cheaper } \\
\text { than traditional cigarette) }\end{array}$ & $\begin{array}{l}\text { The intricacies of their use and maintenance } \\
\text { may hinder widespread adoption }\end{array}$ \\
\hline
\end{tabular}


on electronic cigarettes must be conducted in order to ensure that the decisions of regulators, healthcare providers and consumers are based on evidence based medicine.

In the absence of specific evidence, it is important that currently marketed electronic cigarettes must comply with the best possible quality standards. For example, regulations should ensure that the liquid is manufactured under sanitary conditions and uses pharmaceutical grade or USP grade ingredients, and that a listing of all ingredients and information on the percent of nicotine present, if any, should be explicitly stated.

The dream of a cigarettes - free world is just that - a dream. Nicotine's effects, observed in nicotine consumers, include correcting problems with the ability to remember, pay attention, and concentrate, as well as improving symptoms of mood disorders. Keeping such disabilities at bay right now can be much stronger motivation to continue smoke cigarettes than any threats of diseases that may strike years and years in the future. For smokers unwilling to quit, nicotine's effects can be harnessed and the harmful effects of the delivery mechanism can be attenuated by providing nicotine from less dangerous sources than inhaling tobacco smoke. For these reasons electronic cigarette could become a promising tool - if studied more extensively and deeply - in the fight against tobacco-related morbidity and mortality.

Acknowledgements: Riccardo Polosa is full Professor of Internal Medicine and he is supported by the University of Catania, Italy.

Conflict of Interest: None of the authors have any competing interests to declare, with the exception of RP. RP has received lecture fees from Pfizer and GSK, a research grant from Pfizer, and he served as a consultant for Pfizer, Global Health Alliance for treatment of tobacco dependence, and Arbi Group Srl.

\section{References}

1. World Health Organization (WHO) report on the global tobacco epidemic, 2008. www.who.int/tobacco/mpower/2008/en/index.html

2. US Department of Health and Human Services (2004) The Health Consequences of Smoking: A Report of the Surgeon General, US Department of Health and Human Services, Centers for Disease Control and Prevention, National Center for Chronic Disease Prevention and Health Promotion, Office on Smoking and Health.

3. Doll R, et al. Mortality in relation to smoking: 50 years' observations on male British doctors. BMJ 2004; 328 : 1519-1528.

4. US Department of Health and Human Services (1990) The Health Benefits of Smoking Cessation [DHHS Publication No. (CDC) 90-8516], US Department of Health and Human Services, Public Health Service, Centers for Disease Control, Center for Chronic Disease Prevention and Health Promotion, Office on Smoking and Health.

5. Fiore MC, Jaen CR, Baker TB, et al. Treating tobacco use and dependence: 2008 update. US Dept of Health and Human Services, Public Health Service; May 2008.

6. Parrott S, Godfrey C, Raw M, West R, McNeill A. Guidance for commissioners on the cost effectiveness of smoking cessation interventions. Health Educational Authority. Thorax 1998; 53 Suppl 5 Pt 2: S1-38.

7. Hughes JR, Keely J, Naud S. Shape of the relapse curve and long-term abstinence among untreated smokers. Addiction 2004; 99: 29-38.

8. Caponnetto P, Russo C, Polosa R. Smoking cessation: present status and future perspectives. Curr Opin Pharmacol 2012; 12: 229-37.

9. Hays JT, Ebbert JO. Adverse effects and tolerability of medications for the treatment of tobacco use and dependence. Drugs 2010; 70: 2357-72.

10. Tobacco Advisory Group of the Royal College of Physicians. Harm reduction in nicotine addiction: Helping people who can't quit. October 2007. Royal College of Physicians.

11. Bridgehead International, EQUIPP: Europe Quitting: Progress and Pathways, London, 2011. Equip Report available at: http://www.ersnet.org/images/stories/ weekly/EQUIP_REPORT_COMPLETE.PDF

12. Hon L. A non-smokable electronic spray cigarette: CA 2518174; 2005.

13. Alliance Technologies. Characterization of liquid 'smoke juice' for electronic cigarettes. http://cdn.johnsoncreeksmokejuice.com/downloads/JCE_GCMS_Report.pdf

14. Zezima K. Cigarettes without smoke or regulation. In: New York Times. New York, NY, USA; 2009.

15. Ayers JW, Ribisl KM, Brownstein JS. Tracking the rise in popularity of electronic nicotine delivery systems (electronic cigarettes) using search query surveillance. Am J Prev Med 2011; 40: 448-453.

16. Benowitz NL. Nicotine replacement therapy: what has been accomplished - can we do better? Drugs 1993; 45: 157-170.

17. Johansson CJ, Olsson P, Bende M, Carlsson T, Gunnarsson PO. Absolute bioavailability of nicotine applied to different nasal regions. Eur J Clin Pharmacol 1991; 41: 585-588.

18. Barrett SP. The effects of nicotine, denicotinized tobacco, and nicotinecontaining tobacco on cigarette craving, withdrawal, and selfadministration in male and female smokers. Behav Pharmacol 2010; 21: 144 -52.

19. Dar R, Rosen-Korakin N, Shapira O, Gottlieb Y, Frenk H. The craving to smoke in flight attendants: relations with smoking deprivation,anticipation of smoking, and actual smoking. J Abnorm Psychol 2010; 119: 248 -53.

20. Caponnetto P, Campagna D, Papale G, Russo C, Polosa $\mathrm{R}$. The emerging phenomenon of electronic cigarettes. Expert Rev Respir Med 2012; 6: 63-74.

21. Caponnetto P, Polosa R, Auditore R, Russo C, Campagna D. Smoking Cessation with E-Cigarettes in Smokers with a Documented History of Depression and Recurring Relapses. Int J Clin Med 2011; 2: 281-284.

22. Caponnetto P, Polosa R, Russo C, Leotta C, Campagna D. Successful smoking cessation with electronic cigarettes in smokers with a documented history of recurring relapses: a case series. BMC J Med Case Reports 2011; 5: 585.

23. Polosa R, Caponnetto P, Morjaria JB, Papale G, Campagna D, Russo C. Effect of an Electronic Nicotine Delivery Device (e-Cigarette) on Smoking Cessation and Reduction: A Prospective Pilot Study. BMC Public Health 2011; 11: 786.

24. US Food and Drug Administration. Final Report on FDA Analyses. May 4, (2009). http://www.fda.gov/ downloads/Drugs/ScienceResearch/UCM173250.pdf

25. http://msdssearch.dow.com/PublishedLiterature DOWCOM/dh_0046/0901b80380046c80.pdf?filepath =propyleneglycol/pdfs/noreg/117-01656.pdf\&from Page $=$ GetDoc

26. Laugesen M. Ruyan e-cigarette bench-top tests. Poster. Society for Research on Nicotine and Tobacco. Dublin April (2009). http://www.healthnz.co.nz/DublinEcigBenchtop Handout.pdf 
27. Ben Thomas Group, LLC. Study to Determine Presence of TSNAs in NJOY Vapour. December 9, (2009). Report. http://www.casaa.org/files/Study_TSNAs_in_NJOY Vapour.pdf

28. Cahn Z, Siegel M. Electronic cigarettes as a harm reduction strategy for tobacco control: A step forward or a repeat of past mistakes? J Public Health Policy 2011; 32: $16-31$

29. Baker RR. Smoke generation inside a burning cigarette: Modifying combustion to develop cigarettes that may be less hazardous to health. Progress in Energy and Combustion Science 2006; 32: 373-385.

30. Miura K, Kikukawa Y, Nakao T, et al. Safety Assessment of Electronic Cigarettes in Smokers. Seikatsu Eisei (Journal of Urban Living and Health Association) 2011; 55: 59-64.

31. Wieslander G, Norback D, Lindgren T. Experimental exposure to propylene glycol mist in aviation emergency training: acute ocular and respiratory effects. $O c$ cup Environ Med 2001; 58: 649-655.

32. Varughese S, Teschke K, Brauer M, Chow Y, van Netten C, Kennedy SM. Effects of theatrical smokes and fogs on respiratory health in the entertainment industry. Am J Ind Med 2005; 47: 411-418.

33. Caponnetto P, Cibella F, Mancuso S, Campagna D, Arcidiacono G, Polosa R. Effect of a nicotine free inhalator as part of a smoking cessation program. Eur Respir $J$ 2011; 38: 1005-11

34. Vardavas CI, Anagnostopoulos N, Kougias M, Evangelopoulou V, Connolly GN, Behrakis PK. Short-term pulmonary effects of using an e-cigarette: impact on respiratory flow resistance, impedance and exhaled nitric oxide. Chest 2012; 141: 1400-6.

35. Oostveen E, MacLeod D, Lorino H, et al. The forced oscillation technique in clinical practice: methodology, recommendations and future developments. Eur Respir $J$ 2003; 22: 1026-1041.

36. Dweik RA, Boggs PB, Erzurum SC, et al; American Thoracic Society Committee on Interpretation of Exhaled Nitric Oxide Levels (FENO) for Clinical Applications. An official ATS clinical practice guideline: interpretation of exhaled nitric oxide levels (FENO) for clinical applications. Am J Respir Crit Care Med 2011; 184: 602-15.

37. Stepanov I, Jensen J, Hatsukami D, Hecht SS. Tobaccospecific nitrosamines in new tobacco products. Nicotine Tob Res 2006; 8: 309-13.

38. US Department of Health and Human Services, Centers for Disease Control, Tobacco use compared to other drug dependencies. In The Health Consequences of Smoking: Nicotine Addiction. A Report of the Surgeon General Volume Chapter V. Rockville, MD; 1988.

39. Gehricke JG, Loughlin SE, Whalen CK, et al. Smoking to self-medicate attentional and emotional dysfunctions. Nicotine Tob Res 2007; 9 Suppl 4: S523-36.
40. Benowitz NL. Pharmacology of Nicotine: Addiction, Smoking-Induced Disease, and Therapeutics Annu Rev Pharmacol Toxicol 2009; 49: 57-71.

41. Benowitz N. Nicotine Safety and Toxicity. Oxford University Press; 1998.

42. Polosa R, Benowitz NL. Treatment of nicotine addiction: present therapeutic options and pipeline developments. Trends Pharmacol Sci 2011; 32: 281-9.

43. George TP. Medication Treatments for Nicotine Dependence, CRC/Taylor \& Francis; 2007.

44. Gross J, Stitzer ML. Nicotine replacement: ten-week effects on tobacco withdrawal symptoms. Psychopharmacology (Berl) 1989; 98: 334-341.

45. Etter JF, Bullen C, Electronic cigarettes: users profile, utilization, satisfaction and perceived efficacy. Addiction 2011; 106: 2017-28

46. Heavner K, Dunworth J, Bergen P, Nissen C, Phillips $\mathrm{CV}$. Electronic cigarettes (e-cigarettes) as potential tobacco harm reduction products: results of an online survey of e-cigarette users. Tob Harm Reduction [Internet]; working paper 011 (2011). Available from: http:// www.tobaccoharmreduction.org/wpapers/011.htm anno

47. Siegel MB, Tanwar KL, Wood KS. Electronic cigarettes as a smoking-cessation tool: results from an online survey. Am J Prev Med 2011; 40: 472-5.

48. Goniewicz ML, Zielinska-Danch W, Koszowski B, Czogala J, Sobczak A. Patterns of use of electronic nicotine delivery devices (ENDS) among Polish e-smokers. $12^{\text {th }}$ annual meeting of the Society for Research on Nicotine and Tobacco Europe. Bath, UK; 2010.

49. Chapman S. Public health advocacy and tobacco Control: making smoking history. Oxford: Blackwell; 2007.

50. Foulds J, Ramström L, Burke M, et al. Effect of smokeless tobacco (snus) on smoking and public health in Sweden. Tob Control 2003; 12: 349-359.

51. Norberg M, Lundqvist G, Nilsson M, Gilljam H, Weinehall L. Changing patterns of tobacco use in a middle-aged population: the role of snus, gender, age, and education. Glob Health Action; 4. doi: 10.3402/ gha.v4i0.5613 (2011).

52. Roth D, Roth AB, Liu X. Health risks of smoking compared with Swedish snus. Inhal Toxicol 2005; 17: 741-8.

53. Etter JF. Electronic cigarettes: a survey of users. BMC Public Health 2010; 10: 231.

54. World Health Organization (WHO). Tobacco Fact Sheet N339, May; 2011.

55. Phillips CV, Rabiu D, Rodu B. Calculating the comparative mortality risk from smokeless tobacco versus smoking. Am J Epidemiol 2006; 163: S189.

56. World Health Organization (WHO) Study Group on Tobacco Product Regulation, report on the scientific basis of tobacco product regulation: third report of a WHO study group. WHO technical report series; no. 955.,2009. http://whqlibdoc.who.int/publications/2009/ 9789241209557_eng.pdf (accessed June 2011).

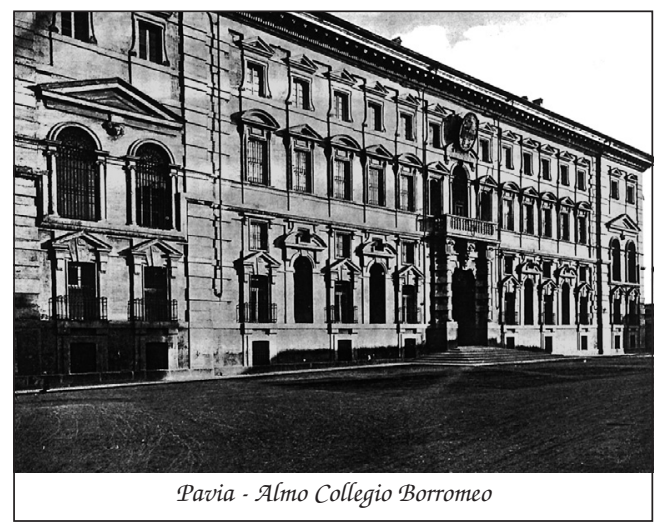

